\title{
Thermal Decomposition of Dichlorosilane Investigated by Pulsed Laser Powered Homogeneous Pyrolysis
}

\author{
Mark T. Swihart and Robert W. Carr
}

Department of Chemical Engineering and Materials Science, University of Minnesota, Minneapolis, Minnesota 55455, USA

\begin{abstract}
Results of the $\mathrm{SF}_{6}$ sensitized infrared pulsed laser powered homogeneous pyrolysis of dichlorosilane are reported. Pyrolyses at temperatures of 1350 to $1700 \mathrm{~K}$ and pressures of 150 to 230 Torr with reaction times around $7 \mu \mathrm{s}$ were carried out in the presence and absence of molecules that could potentially scavenge the primary decomposition products $\left(\mathrm{SiHCl}\right.$ and/or $\mathrm{SiCl}_{2}$ ). We were unable to irreversibly trap the reaction products, but obtained upper limits for the unimolecular decomposition rate constant under these conditions by measuring reactant loss. The observed rates are consistent with the high activation energy for dichlorosilane decomposition, near $75 \mathrm{kcal} / \mathrm{mol}$, that is predicted by $a b$ initio calculations.
\end{abstract}

\section{Introduction}

The homogeneous thermal decomposition of dichlorosilane is potentially important in the high temperature chemical vapor deposition (CVD) of epitaxial silicon because it can produce reactive species $\left(\mathrm{SiHCl}, \mathrm{SiCl}_{2}\right)$ that can contribute to film growth with much higher probability than the parent molecule. However, the rate and dominant reaction path for the decomposition remain uncertain. The two lowest energy pathways for decomposition are

$$
\begin{aligned}
& \mathrm{SiH}_{2} \mathrm{Cl}_{2} \rightarrow \mathrm{SiCl}_{2}+\mathrm{H}_{2} \quad \Delta H_{298}^{\circ}=36 \mathrm{kcal} / \mathrm{mol} \\
& \mathrm{SiH}_{2} \mathrm{Cl}_{2} \rightarrow \mathrm{SiHCl}+\mathrm{HCl} \quad \Delta H_{298}^{\circ}=67 \mathrm{kcal} / \mathrm{mol}
\end{aligned}
$$

High level $a b$ initio calculations by Schlegel and co-workers $^{1,2}$ predict comparable barriers for the two reactions. Calculated barriers (electronic plus zero point energy) range from 73 to $76 \mathrm{kcal} / \mathrm{mol}$ for $\mathrm{SiCl}_{2}$ elimination and 71 to $74 \mathrm{kcal} / \mathrm{mol}$ for $\mathrm{SiHCl}$ elimination, with the latter channel consistently $2 \mathrm{kcal} / \mathrm{mol}$ lower. ${ }^{2}$ This, combined with a larger predicted pre-exponential for $\mathrm{SiHCl}$ elimination leads to dominance of that path by a factor of 20 at $600^{\circ} \mathrm{C}$. In IR multiphoton dissociation experiments, Sausa and Ronn ${ }^{3}$ detected electronically excited $\mathrm{SiCl}_{2}$. Walker et al. ${ }^{4}$ decomposed dichlorosilane in both static pyrolysis experiments and using a single-pulse shock tube. They concluded that the decomposition products were $\mathrm{SiCl}_{2}$ and $\mathrm{H}_{2}$. Kruppa et $a l .{ }^{5}$ found that $\mathrm{SiCl}_{2}$ and $\mathrm{HCl}$ were the primary products of vacuum flash pyrolysis of $\mathrm{SiH}_{2} \mathrm{Cl}_{2}$. Ban and Gilbert ${ }^{6}$ observed $\mathrm{SiCl}_{2}$ by mass spectrometry under silicon chemical vapor deposition (CVD) conditions, but Ho and Brieland ${ }^{7}$ observed $\mathrm{SiHCl}$ by laser induced fluorescence in a silicon CVD reactor. Ho et al. ${ }^{8}$ observed that $193 \mathrm{~nm}$ photolysis of $\mathrm{SiH}_{2} \mathrm{Cl}_{2}$ produced $\mathrm{SiHCl}$. Two detailed kinetic models of epitaxial silicon CVD from dichlorosilane postulated deposition mechanisms and adjusted the rate parameters for dichlorosilane decomposition to fit the observed deposition rates. Hierlemann et al. ${ }^{9}$ assumed the reaction was in the low pressure limit and fit rate parameters of $A=10^{16}\left(\mathrm{~mol} / \mathrm{cm}^{3}\right)^{-1} \mathrm{~s}^{-1}$ and $E_{\mathrm{a}}=40.0 \mathrm{kcal} / \mathrm{mol}$. Knutson et al. ${ }^{10}$ treated the reaction as first order, and fit an activation energy of $E_{\mathrm{a}}=60.0 \mathrm{kcal} / \mathrm{mol}$ with $A=1.38 \times$ $10^{8} \mathrm{~T}^{2} \mathrm{~s}^{-1}$. Both of these expressions have activation energies that are much lower, and hence decomposition rates that are much higher, than would be predicted based on the $a b$ initio calculations.

In this work, we decomposed dichlorosilane via $\mathrm{SF}_{6}$ photosensitized infrared pulsed laser powered homogeneous pyrolysis (LPHP), incorporating probe laser measurement of reaction time and temperature. ${ }^{11}$ This technique allows us to achieve high reaction temperatures with short reaction times, which minimizes the effects of secondary reactions in the gas phase. No heterogeneous reactions occur in these experiments because only the gas is heated, while the reactor walls remain at room temperature. Effective rate parameters were obtained from measurements of overall reactant loss after a large number of laser pulses. We were unable to chemically trap the reactive products, and therefore cannot conclude which reaction path, if either, was dominant. However, the observed rate coefficients do allow us to obtain an upper limit for the decomposition rate at the experimental conditions. These results support a high activation energy, near $75 \mathrm{kcal} / \mathrm{mol}$, as predicted by the $a b$ initio calculations.

\section{Experimental}

These experiments were carried out using the same equipment and techniques we have described previously. ${ }^{12}$ Briefly, a Lumonics Model TEA 101-2 pulsed $\mathrm{CO}_{2}$ laser was used to heat reaction mixtures containing reactants, bath gas, and sulfur hexafluoride as a photosensitizer. The laser was tuned to the $\mathrm{P}(16)$ line of the $\mathrm{CO}_{2}$ transition, with a wavelength of $10.55 \mu \mathrm{m}$. Dichlorosilane absorbs at this wavelength, which is the same one used for IR multiphoton dissociation of $\mathrm{SiH}_{2} \mathrm{Cl}_{2}$ by Sausa and Ronn. ${ }^{3}$ However, they observed no detectable dissociation at fluences comparable to those used in these experiments. The extinction coefficient for absorption by $\mathrm{SF}_{6}^{12}$ is about 150 times that for $\mathrm{SiH}_{2} \mathrm{Cl}_{2}$ at this wavelength at room temperature, so clearly the vast majority of energy transferred into the mixture is absorbed by $\mathrm{SF}_{6}$, and absorption by $\mathrm{SiH}_{2} \mathrm{Cl}_{2}$ will have a negligible effect. The reaction cell was constructed from 1 in. od Pyrex tubing, and had a length of $3.05 \mathrm{~cm}$ between the windows and a volume of $4.83 \mathrm{~cm}^{3}$. $\mathrm{NaCl}$ windows were used in some of the preliminary experiments, but it appeared that reaction of $\mathrm{SiH}_{2} \mathrm{Cl}_{2}$ with water adsorbed on the windows might be occurring. All kinetic data were obtained with ZnSe windows on the reactor, which eliminated this problem. The reaction time was determined by monitoring the thermal lens effect of the reactor contents on a $\mathrm{HeNe}$ laser aligned coaxially with the $\mathrm{CO}_{2}$ laser, as described previously. ${ }^{11}$ The temperature was calculated from the speed of sound, which was determined from the thermal lens signal, as also described previously ${ }^{11,13}$ Due to the high activation energy for decomposition and significant fall-off effects, these experiments required temperatures in the range of 1350 to $1700 \mathrm{~K}$. These are higher temperatures than we have previously used in the LPHP experiment.

At such high temperatures we must consider the possibility that higher energy decomposition paths could be important. The silicon hydrogen bond has a bond dissociation energy of about $92 \mathrm{kcal} / \mathrm{mol}$. The simple bond breaking reaction

$$
\mathrm{SiH}_{2} \mathrm{Cl}_{2} \rightarrow \mathrm{SiHCl}_{3}+\mathrm{H}
$$

would be expected to have a large pre-exponential factor $\left(10^{16}\right.$ to $10^{16.5}$ ) and an activation energy close to the bond dissociation energy. At high pressures, this reaction could start to contribute significantly at temperatures near 1700 $\mathbf{K}$. However, in the unimolecular falloff regime where these 


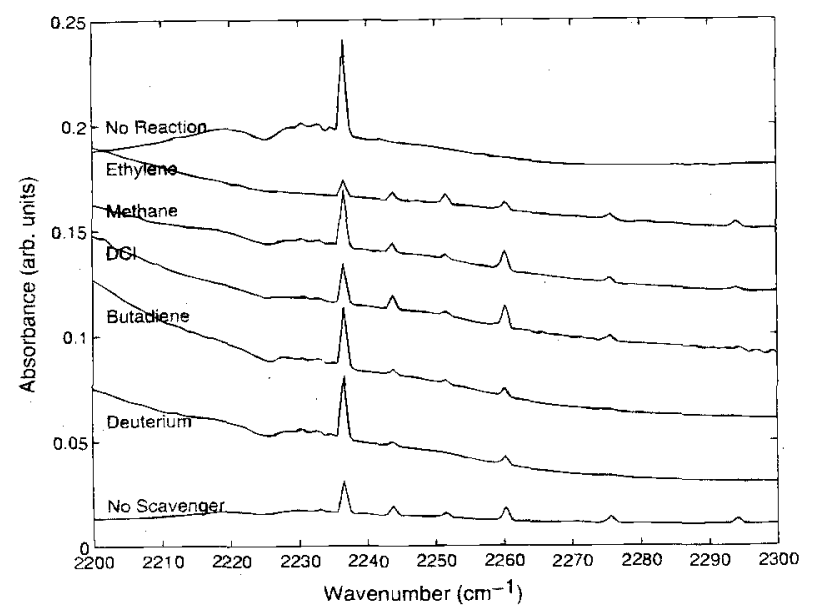

Fig. 1. Spectra near the dichlorosilane stretching peak at $2237 \mathrm{~cm}^{-1}$ before reaction and after reaction with and without potential scavenging species added. Curves are labeled by the added species.

experiments were conducted, this high energy path is slowed much more than the lower energy paths. Multichannel RiceRamsberger-Kassel-Marcus theory for unimolecular reactions (RRKM) calculations indicate that this reaction is roughly 1000 times slower than $\mathrm{SiHCl}$ elimination under reaction conditions used here. Breaking of the silicon chlorine bond, with a bond dissociation energy near $110 \mathrm{kcal} / \mathrm{mol}$, will clearly be even slower.

Chemicals used were dichlorosilane (Aldrich, 99.99\%), sulfur hexafluoride (Matheson, CP grade), and nitrogen (Air Products, ultrahigh purity grade). Product analysis was by Fourier transform infrared spectroscopy (FTIR) using a Nicolet Magna 740 FTIR. Spectra were taken before and after the LPHP experiment. Quantitative measurement of reactant loss was obtained by comparison of these spectra utilizing the sharp dichlorosilane Si-H stretching peak at $2237 \mathrm{~cm}^{-1}$. Product analysis by gas chromatography (Shimadzu Model 14A with thermal conductivity detector) was also attempted, but due to the small sample quantity and high reactivity of dichlorosilane with adsorbed water, it was difficult to fully eliminate hydrolysis of dichlorosilane. Reasonable results were obtained on a $12 \mathrm{ft}$ by $1 / 4 \mathrm{in}$. Teflon column packed with $20 \%$ SF-96 on Chromosorb P-AW. Careful pretreatment of the sampling system with dichlorosilane to remove adsorbed water was required. Measurements of reactant loss by gas chromatography (GC) would not allow us significantly greater precision than determination by FTIR, so all kinetic data presented here were obtained from reactant loss measured by FTIR.

We carried out several experiments with a trapping agent added to the reaction mixture in an attempt to irreversibly capture the $\mathrm{SiHCl}$ or $\mathrm{SiCl}_{2}$ produced by dichlorosilane decomposition. Trapping agents used were $\mathrm{D}_{2}, \mathrm{DCl}$, ethylene, 1,3-butadiene, and methane. Identification of a single final product produced would have allowed us to identify the dominant reaction channel. Additionally, the ability to identify and measure small quantities of a product would have allowed us to make measurements at much lower conversions of reactant than was possible when measuring reactant loss. This would have allowed us to work at lower temperatures where the LPHP experiment is better established. However, none of these species was successful in trapping the $\mathrm{SiHCl}$ or $\mathrm{SiCl}_{2}$ to give a single, stable, identifiable compound. Nonetheless, we can glean some information from the results of these experiments.

\section{Results and Discussion}

The infrared spectra of reaction mixtures after the LPHP experiment showed the presence of multiple products which were neither firmly identifiable nor quantifi- able. This was true both in the presence and absence of additional species which might have scavenged the reactive $\mathrm{SiHCl}$ or $\mathrm{SiCl}_{2}$ produced. Figure 1 shows the infrared spectrum in the Si-H stretching region before and after reaction, and with the addition of several other compounds. Differences in peak size are primarily due to differences in extent of reaction. The peak at $2237 \mathrm{~cm}^{-1}$ is the $\mathrm{Si}$ $\mathrm{H}$ stretch of dichlorosilane. The product peak at $2260 \mathrm{~cm}^{-1}$ is most likely the corresponding mode in trichlorosilane. The corresponding peaks for monochlorosilane at $2211 \mathrm{~cm}^{-1}$ and silane at $2189 \mathrm{~cm}^{-1}$ were not observed. The other product peaks at $2244,2252,2276$, and $2294 \mathrm{~cm}^{-1}$ are not readily assigned to a $\mathrm{Si}-\mathrm{H}-\mathrm{Cl}$ compound, although they could be due to higher partially chlorinated silanes. The IR spectroscopy of the chlorinated disilanes is not well known, but spectra of the mono-, di-, and trichlorodisilanes ${ }^{14}$ and $a b$ initio calculations for all of the chlorinated disilanes ${ }^{15}$ indicate that their $\mathrm{Si}-\mathrm{H}$ stretches should all be at smaller wave numbers than the $\mathrm{Si}-\mathrm{H}$ stretches in dichlorosilane. No peaks are observed in that region. $\mathrm{HCl}$ was observed in the product spectra but was not proportional to the amount of dichlorosilane lost. No additional peaks other than those of $\mathrm{SiH}_{2} \mathrm{Cl}_{2}$ and $\mathrm{SF}_{6}$ were observed in the IR spectrum from 600 to $4000 \mathrm{~cm}^{-1}$. GC analysis of reaction products with thermal conductivity detection indicated the presence of compounds that had residence times consistent with $\mathrm{HCl}$, monochlorosilane, and trichlorosilane. These peaks were not quantified, but were clearly too small to account for the amount of dichlorosilane which had reacted away. No other product peaks were observed in the GC analysis, although compounds with boiling points substantially higher than trichlorosilane could have eluted in small quantities with peaks so broadened as to be undetectable.

Molecular deuterium and deuterium chloride were independently added to the reaction mixture as scavengers in 10 to 20 -fold excess over dichlorosilane. $\mathrm{SiHCl}$ or $\mathrm{SiCl}_{2}$ could potentially insert into these diatomics to give deuterated chlorosilanes. As seen in Fig. 1, the product peaks were the same as without any scavenger. More important, none of the Si-D stretching frequencies in the 1600 to $1700 \mathrm{~cm}^{-1}$ range that would be expected from the deuterated chlorosilanes were observed. We can therefore conclude that no significant amount of insertion into $\mathrm{D}_{2}$ or $\mathrm{DCl}$ occurred, and these insertions must be slower than competing processes that occur in their absence. Insertion into $\mathrm{D}_{2}$ and $\mathrm{DCl}$ would have approximately the same rate parameters as insertion into $\mathrm{H}_{2}$ and $\mathrm{HCl}$, respectively (modified by isotope effects). Therefore we can conclude that insertions into $\mathrm{H}_{2}$ and $\mathrm{HCl}$, which are the reverse reactions of the primary decomposition steps, do not occur. These observations are consistent with $a b$ initio calculations ${ }^{2}$ that predict significant barriers for insertion of $\mathrm{SiHCl}$ and $\mathrm{SiCl}_{2}$ into both $\mathrm{H}_{2}$ and $\mathrm{HCl}$. Methane, ethylene, and butadiene were also tried as scavengers. Methane appeared to have no effect on the product spectrum. Both ethylene and butadiene addition resulted in an identical small peak at $730 \mathrm{~cm}^{-1}$, but no other qualitative differences from the results in their absence. The product peaks from 2240 to $2300 \mathrm{~cm}^{-1}$ were unchanged. Thus, the decomposition products may have reacted with $\mathrm{C}=\mathrm{C}$ double bonds at a rate comparable to the other processes occurring, but this was not the dominant process and did not give a single stable quantifiable product.

Likely reactions for $\mathrm{SiHCl}$ or $\mathrm{SiCl}_{2}$ to undergo after eliminating from dichlorosilane are insertion into dichlorosilane and dimerization. Ab initio calculations predict barriers (electronic plus zero point energy) of 2 and $10 \mathrm{kcal} / \mathrm{mol}$ for insertion of $\mathrm{SiHCl}$ and $\mathrm{SiCl}_{2}$, respectively, into dichlorosilane. ${ }^{15}$ We would expect the dimerization reactions to occur without a barrier. Under the conditions of these experiments, the average conversion, per laser pulse, in the laser heated region ranged from 0.02 to $0.35 \%$. So, after a laser pulse, dichlorosilane concentrations are of order $10^{17}$ molecule/ $\mathrm{cm}^{3}$, while $\mathrm{SiHCl}$ and $\mathrm{SiCl}_{2}$ concentrations are of order $10^{14}$ molecule $/ \mathrm{cm}^{3}$. Rate con- 
stants for insertion into dichlorosilane can be estimated from the $a b$ initio energies and structures ${ }^{15}$ using conventional transition state theory. Dimerization rates should be near the gas kinetic collision frequency. At $1550 \mathrm{~K}$, a typical reaction temperature, we estimate rates to be

$\mathrm{SiHCl}+\mathrm{SiH}_{2} \mathrm{Cl}_{2}, k=1 \times 10^{-13} \mathrm{~cm}^{3} /($ molecule s)

$$
\text { rate }=1 \times 10^{18} \text { molecule } /\left(\mathrm{cm}^{3} \mathrm{~s}\right)
$$

$\mathrm{SiCl}_{2}+\mathrm{SiH}_{2} \mathrm{Cl}_{2}, k=5 \times 10^{-15} \mathrm{~cm}^{3} /($ molecule $\mathrm{s})$

rate $=5 \times 10^{16}$ molecule $/\left(\mathrm{cm}^{3} \mathrm{~s}\right)$

$\mathrm{SiHCl}+\mathrm{SiHCl}, k=1 \times 10^{-10} \mathrm{~cm}^{3} /($ molecule $\mathrm{s})$,

rate $=1 \times 10^{18}$ molecule $/\left(\mathrm{cm}^{3} \mathrm{~s}\right)$

$\mathrm{SiCl}_{2}+\mathrm{SiCl}_{2}, k=1 \times 10^{-10} \mathrm{~cm}^{3} /($ molecule $\mathrm{s})$,

$$
\text { rate }=1 \times 10^{18} \text { molecule } /\left(\mathrm{cm}^{3} \mathrm{~s}\right)
$$

So, under these conditions, the dimerization rate is much faster than insertion of $\mathrm{SiCl}_{2}$ into dichlorosilane and comparable to insertion of $\mathrm{SiHCl}$ into dichlorosilane. Very little of either process occurs during the $7 \mu$ s or so that the mixture is at the reaction temperature. The maximum amount of $\mathrm{SiHCl}$ insertion into dichlorosilane, for example, is

$\left(1 \times 10^{18}\right.$ molecule $\left./ \mathrm{cm}^{3} / \mathrm{s}\right)\left(7 \times 10^{-6} \mathrm{~s}\right)$

$$
\begin{aligned}
& =7 \times 10^{12} \mathrm{molecule} / \mathrm{s} \\
& =7 \% \text { of } \mathrm{SiHCl} \text { produced }
\end{aligned}
$$

This tells us that no significant amount of dichlorosilane can be consumed by secondary reactions during the initial reaction time of a few microseconds.

The temperature drop across the expansion wave that initially cools the reactive region is 150 to $200 \mathrm{~K}$ under these conditions. This quenches the unimolecular decomposition to a rate that is negligible in comparison to its rate before cooling. However, the lower activation energy secondary processes can continue to occur as additional cooling takes place. The temperature history after the initial expansion cooling is not known quantitatively. Additional acoustic waves propagate on the same microsecond time scale as the initial expansion and mix the hot gas with the surrounding cool gas. Complete mixing would lead to a temperature around $400 \mathrm{~K}$, because only about $8 \%$ of the gas in the reactor is heated, while the rest remains at room temperature. Estimates of conductive cooling for the beam diameter and gas mix used in these experiments indicate that significant cooling at the center of the heated region due to conduction occurs on a time scale of 0.2 to $1 \mathrm{~ms}$. So, secondary chemistry could continue to occur for several hundred microseconds after the initial reaction period. As the temperature drops, insertion of $\mathrm{SiHCl}$ and $\mathrm{SiCl}_{2}$ into dichlorosilane will slow down, while dimerization will not, since it has no barrier. Thus, the dominant bimolecular reactions during the cooling period will be dimerization. At high temperatures, the dimers can fall back apart to reproduce the chlorinated disilanes, and could also possibly isomerize to chlorinated silysilylenes and subsequently insert into dichlorosilane, but as the temperature drops, these processes will slow down, and the dimers will only be able to recombine with each other to give higher polychlorosilanes.

The most likely final fate for the $\mathrm{SiHCl}$ or $\mathrm{SiCl}_{2}$ produced by the unimolecular decomposition then seems to be combination to give polychlorosilanes which may then deposit on the walls, explaining the scarcity of observable reaction products. Before combining, these reactive molecules may consume some dichlorosilane through chain processes involving insertion of $\mathrm{SiHCl}$ and $\mathrm{SiCl}_{2}$ into dichlorosilane. The time scale of these experiments, however, is too short for long chains to occur. Suppose, for example, that $\mathrm{SiHCl}$ continued to insert into dichlorosilane at the rate of $10^{18}$ molecule $/\left(\mathrm{cm}^{3} \mathrm{~s}\right)$, as estimated above at the reaction temperature, for $100 \mu \mathrm{s}$. Then the amount of dichlorosilane consumed by this secondary reaction would be

$$
\left(10^{18} \text { molecule } /\left(\mathrm{cm}^{3} \mathrm{~s}\right)\right) \times\left(10^{-4} \mathrm{~s}\right)=10^{14} \mathrm{molecule} / \mathrm{cm}^{3}
$$

This is an amount equal to the amount of dichlorosilane consumed by the initial unimolecular decomposition, corresponding to a chain length of 2 . This assumes that subsequent steps regenerate the $\mathrm{SiHCl}$ so that its concentration remains constant and that the insertion of $\mathrm{SiHCl}$ into dichlorosilane consumes dichlorosilane irreversibly. In fact, $a b$ initio calculations ${ }^{15}$ indicate that the fastest reaction of the $\mathrm{HCl}_{2} \mathrm{SiSiH}_{2} \mathrm{Cl}$ produced by $\mathrm{SiHCl}$ insertion into dichlorosilane is decomposition back to $\mathrm{SiHCl}$ and dichlorosilane. Since insertion of $\mathrm{SiCl}_{2}$ into dichlorosilane is 20 or more times slower than insertion of $\mathrm{SiHCl}$ into dichlorosilane, $\mathrm{SiCl}_{2}$ insertion can consume negligible amounts of dichlorosilane compared to $\mathrm{SiHCl}$ insertion. We, therefore, believe that while some dichlorosilane may be consumed in secondary reactions, the amount consumed can, at most, be an amount comparable to that produced by the initial unimolecular decomposition.

Results of decomposition of dichlorosilane in the absence of any scavenging species are presented in Table I. The reaction time is the time required for the expansion wave induced by the laser heating to reach the axis of the laser-heated region. The temperature is calculated from the speed of this wave, which is the speed of sound at the reaction temperature. The rate constant is calculated from the fraction of reactant remaining, the number of pulses, and the reaction time. The rate constants have been corrected for reactions occurring during and after the expansion wave cooling. These calculations and corrections are described in detail in our previous work ${ }^{11,13}$ Briefly, the rate constant is given by

$$
k=f\left(3 / t_{\mathrm{r}}\right)\left(V_{\mathrm{T}} / V_{\mathrm{I}}\right)\left[1-(1-x)^{(1 / n)}\right]
$$

where $x=$ measured reactant conversion, $V_{\mathrm{T}}=$ total reac-

\begin{tabular}{|c|c|c|c|c|c|c|c|c|c|}
\hline $\begin{array}{c}\text { Run } \\
\text { no. }\end{array}$ & $\begin{array}{l}p_{\mathrm{SiH}_{2} \mathrm{Cl}_{2}} \\
\text { (Torr) }\end{array}$ & $\begin{array}{c}p_{\mathrm{SF}_{6}} \\
\text { (Torr) }\end{array}$ & $\begin{array}{c}p_{\mathrm{Ng}_{\mathrm{g}}} \\
\text { (Torr) }\end{array}$ & $\begin{array}{l}p_{\text {total }} \\
\text { (Torr) }\end{array}$ & $\begin{array}{l}\text { Number } \\
\text { of pulses }\end{array}$ & $\begin{array}{l}\text { Reaction } \\
\text { time }(\mu s)\end{array}$ & $C / C_{o}$ & $\begin{array}{l}\text { Calculated } \\
\qquad T(\mathrm{~K})\end{array}$ & $\begin{array}{c}k \\
\left(s^{-1}\right)\end{array}$ \\
\hline 1 & 14.4 & 42.9 & 173.5 & 230.8 & 4350 & 6.40 & 0.92 & 1394 & 74 \\
\hline 2 & 15.8 & 47.1 & 134.7 & 197.6 & 4200 & 6.72 & 0.82 & 1462 & 156 \\
\hline 3 & 15.2 & 45.5 & 128.3 & 189.1 & 4500 & 6.71 & 0.82 & 1473 & 144 \\
\hline 4 & 16.4 & 48.9 & 1117 & 177.0 & 4200 & 6.91 & 0.67 & 1519 & 280 \\
\hline 5. & 17.0 & 50.9 & 101.4 & 169.3 & 4200 & 7.00 & 0.57 & 1566 & 362 \\
\hline 6 & 16.9 & 50.5 & 95.9 & 163.4 & 4200 & 7.08 & 0.63 & 1560 & 291 \\
\hline 8 & 17.9 & 53.5 & 76.8 & 148.2 & 3750 & 7.18 & 0.31 & 1687 & 685 \\
\hline 9 & 178 & 531 & 74.9 & 145.8 & 3000 & 7.20 & 0.31 & 1692 & 846 \\
\hline 10 & 17.0 & 50.7 & 83.0 & 150.7 & 3000 & 7.21 & 0.42 & 1593 & 702 \\
\hline
\end{tabular}
tor volume, $V_{\mathrm{I}}$ = volume irradiated by the infrared laser, $n$ $=$ number of laser pulses, $t_{\mathrm{r}}=$ reaction time (per pulse), and $f$ is a correction factor for reaction occurring during and after the initial expansion wave cooling. ${ }^{11}$

Table I. Decomposition data.

Partial and total pressures given are at the reaction temperature after laser heating. $C / C_{0}$ is the fraction of initial reactant remaining after the total number of laser pulses. $T$ and $k$ are calculated as described in the text and in Ref. 11 and 13 . 
Under experimental conditions, the reaction is well into the unimolecular falloff regime. Pressure, temperature, and mixture composition all vary from data point to data point, as seen in Table I. We have, therefore, corrected all of the data to the high pressure limit. Falloff effects were calculated by solving the master equation for the conditions of each data point. All of these calculations were carried out using programs from the UNIMOL suite of codes by Gilbert et al. ${ }^{16}$. The microcanonical rate constants were obtained from RRKM calculations using energies and structures from the published $a b$ initio calculations. ${ }^{2}$ Barriers of 73.1 and $75.1 \mathrm{kcal} / \mathrm{mol}$ were used for $\mathrm{SiHCl}$ and $\mathrm{SiCl}_{2}$ elimination, respectively. Reactant and transition state geometries and frequencies were those calculated at the MP2/6-31G(d,p) level. ${ }^{2}$ Mixture averaged molecular weights and Lennard-Jones parameters were used in calculating the collision rates and energy transfer. Energy transfer parameters were estimated using the biased random walk model of Lim and Gilbert. ${ }^{17}$ This gave values of the average energy removed per collision $\left(\langle\Delta E\rangle_{\text {down }}\right)$ of 750 to $970 \mathrm{~cm}^{-1}$, and corresponding collision efficiencies that were nearly constant at $\beta=0.13$. These values are reasonable when compared to data on similar systems at comparable temperatures. ${ }^{18,19}$

The data corrected to the high pressure limit as described above are shown in Fig. 2. The line through the data was obtained by holding the pre-exponential factor fixed at $10^{14.8} \mathrm{~s}^{-1}$ and fitting the activation energy. This is the value of the pre-exponential factor predicted based on reactant and transition state structures from the $a b$ initio calculations. $^{2}$ This gave an activation energy of 75.4 $\mathrm{kcal} / \mathrm{mol}$, which is consistent with the predictions of the $a b$ initio calculations. This gives a reasonable fit to the data, showing that our measured rate constants are consistent with the predictions from the ab initio calculations. A slightly better fit could be obtained with a lower activation energy and lower pre-exponential factor. Since some dichlorosilane may be consumed by secondary reactions, as discussed above, our rate constants are upper limits for the actual unimolecular rate constant at these conditions. The amount of dichlorosilane consumed by secondary reactions, relative to that consumed by the unimolecular decomposition, should decrease with increasing temperature since the secondary chemistry is much less temperature dependent than the unimolecular decomposition. This would lower the apparent activation energy. The other

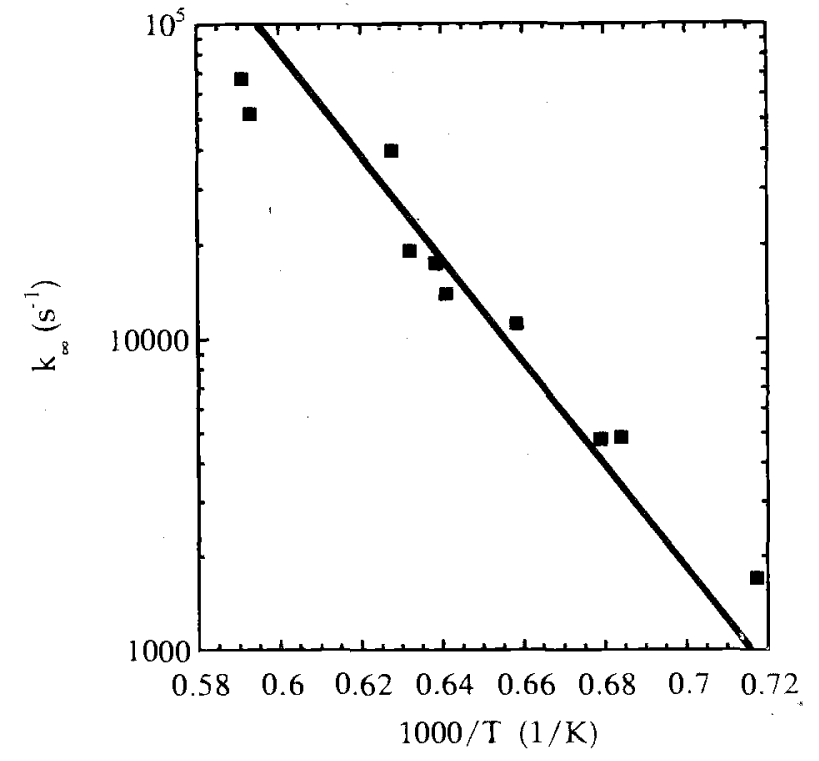

Fig. 2. Arrhenius plot of data corrected to the high pressure limit as described in the text. The squares are the individual measurements, and the line results from fitting the activation energy to the data, holding the pre-exponential fixed at $10^{14.8} \mathrm{~s}^{-1}$. most likely source of error is the temperature measurement. The temperatures used here are higher than we have previously used in the LPHP experiment, and there may be complications that were not observed at lower temperatures.

Even with these uncertainties, it is clear that our data is much more consistent with the $a b$ initio predictions than with the dichlorosilane decomposition rate parameters that have previously been used in modeling silicon epitaxy from dichlorosilane. For example, the rate parameters used by Knutson et al. ${ }^{10}$ give rate constants roughly 100 times larger than those in Fig. 2 at these temperatures, and the difference becomes even greater at lower temperatures. This illustrates the hazards inherent in attempting to obtain rate parameters for individual reaction steps from film growth rates using a detailed reactor model, as was done in Ref. 9 and 10. The rates obtained in that way are dependent on the rates of many other chemical and physical processes occuring in the reactor, and on the reaction mechanisms in the gas phase and at the surface. Since these are generally not completely known, the rate parameters obtained by fitting can exhibit large and unpredictable errors. This means that, while the resulting model may work well over the range of conditions used in the fitting, it will have limited predictive capability over a wider range of conditions. Independent studies of key reaction steps, such as the one presented here, are needed to obtain rate parameters for elementary reactions that can be used in reactor models that are predictive over a wide range of operating conditions.

\section{Conclusions}

Dichlorosilane decomposition was investigated by pulsed infrared laser powered homogeneous pyrolysis. Upper limits on the rate constant for the unimolecular decomposition at 1350 to $1700 \mathrm{~K}$ were obtained from measurements of reactant loss. The reactive products of decomposition could not be quantitatively and irreversibly trapped. The observed rate constants were roughly consistent with $a b$ initio predictions,,${ }^{1,2}$ and were much smaller than those used in previously published models of silicon epitaxy from dichlorosilane.,

\section{Acknowledgments}

MI.T.S. would like to thank the National Science Foundation and the University of Minnesota for support in the form of graduate fellowships.

Manuscript received June 11, 1997.

\section{REFERENCES}

1. J. M. Wittbrodt and H. B. Schlegel, Chem. Phys. Lett., 265, 527 (1997).

2. M.-D. Su and H. B. Schlegel, J. Phys. Chem., 97, 9981 (1993).

3. R. C. Sausa and A. M. Ronn, Chem. Phys., 96, 183 (1985)

4. K. W. Walker, R. E. Jardine, M. A. Ring, and H. E. O'Neal, Personal communication.

5. G. H. Kruppa, S. K. Shin, and J. L. Beauchamp, J. Phys. Chem., 94, 327 (1990).

6. V. S. Ban and S. L. Gilbert, This Journal, 122, 1382. (1975).

7. P. Ho and W. G. Breiland, Appl. Phys. Lett., 43, 125 (1983).

8. P. Ho, W. G. Breiland, and R. W. Carr, Chem. Phys. Lett., 132, 422 (1986).

9. M. Hierlemann, A. Kersch, C. Werner, and H. Schäfer, This Journal, 142, 259 (1995).

10. K. L. Knutson, R. W. Carr, W. H. Liu, and S. A. Campbell, J. Cryst. Growth, 140, 191 (1994).

11. M. T. Swihart and R. W. Carr, Int. J. Chem. Kinet., 28, $817(1996)$

12. V. N. Nowak and J. L. Lyman, J. Quant. Spectrosc. Radiat. Transfer, 15, 945 (1975).

13. M. T. Swihart and R. W. Carr, Int. J. Chem. Kinet., 26 779 (1994).

14. R. P. Hollandsworth and M. A. Ring, Inorg. Chem., 7, 1635 (1968).

15. M. T. Swihart and R. W. Carr, J. Phys. Chem., A, 101, 7434 (1997). 
16. R. G. Gilbert, S. C. Smith, and M. J. T. Jordán, UNIMOL program suite (calculation of falloff curves for unimolecular and recombination reactions) (1993). Available from the authors: School of Chemistry Sydney University, NSW 2006, Australia, or by e-mail to gilbert-r@summer.chem.su.oz.au

17. K. F. Lim and R. G. Gilbert, J. Chem. Phys., 92, 1819 (1990).

18. I. Oref and D. C. Tardy, Chem. Rev, 90, 1407 (1990)

19. D. C. Tardy and B. S. Rabinovitch, ibid., 77, 369 (1977).

\title{
Oxygen Permeation Properties of Dense $\mathrm{Bi}_{1.5} \mathrm{Er}_{0.5} \mathrm{O}_{3}-\mathrm{Ag}$ Cermet Membranes
}

\author{
J. E. ten Elshof, N. Q. Nguyen, M. W. den Otter, and H. J. M. Bouwmeester \\ Department of Chemical Technology, Laboratory of Inorganic Materials Science, University of Twente, \\ 7500 AE Enschede, The Netherlands
}

\begin{abstract}
Oxygen permeation experiments were performed on dense mixed-conducting ceramic-metal composite membranes (thickness 0.2 to $2 \mathrm{~mm}$ ) $\mathrm{Bi}_{1.5} \mathrm{Er}_{0.5} \mathrm{O}_{3}$ - Ag with 10.0, 27.8, and 40.0 volume percent (v/o) silver, respectively, in the temperature range 873 to $993 \mathrm{~K}$ and oxygen partial pressure range $10^{-3.5}$ to 1 bar $\mathrm{O}_{2}$. The oxygen fluxes increased with increasing silver content. In the cermets with a nonpercolative silver phase $(10.0$ and $27.8 \mathrm{v} / \mathrm{o})$, the increased oxygen flux relative to that of pure $\mathrm{Bi}_{1.5} \mathrm{Er}_{0.5} \mathrm{O}_{3}$ was attributed to faster kinetics of surface oxygen exchange in the presence of silver. Percolativity of the silver phase in the $40 \mathrm{v} / \mathrm{o}$ Ag composition enhances the ambipolar diffusion of oxygen ions and electrons. High oxygen fluxes $\left(\sim 0.25 \mathrm{mmol} \mathrm{m}{ }^{-2} \mathrm{~s}^{-1}\right.$ at $\left.873 \mathrm{~K}\right)$ were observed with the latter composition, which were shown to be fully limited by the surface exchange kineties. The activation energy for oxygen permeation in the temperature range 848 to 1003 $\mathrm{K}$ is about 85 to $95 \mathrm{~kJ} / \mathrm{mol}$ for the compositions without percolativity of silver and $115 \mathrm{~kJ} / \mathrm{mol}$ for the composite with 40 v/o Ag, which reflects a change of the rate-limiting step upon passing the percolation threshold. Results from both permeation and isotopic exchange measurements on the composition with Ag percolativity indicated the kinetic order of the surface process in oxygen to be $1 / 4$, indicating a process fundamentally different from that on pure $\mathrm{Bi}_{1.5} \mathrm{Er}_{0.5} \mathrm{O}_{3}$.
\end{abstract}

\section{Introduction}

The high-temperature face-centered cubic (fcc) $\delta$-phase of the defect fluorite-type $\mathrm{Bi}_{2} \mathrm{O}_{3}$ is the best oxygen ion conductor known. Its anomalously high ionic conductivity is related to the cubic crystal structure, the nature of the bismuth ion, and the intrinsically large concentration of vacant sites in the oxygen sublattice, which equals $25 \%$ of the total number of crystallographic sites available. The temperature range in which the $\delta$-phase is stable is rather narrow (1002 to $1097 \mathrm{~K}$ ), and the transition from the $\delta$ phase to the low-temperature $\alpha$-phase is accompanied by a conductivity decrease of two to three orders of magnitude. The more conductive cubic phase can be stabilized down to room temperature by partial doping with rare earth elements or $y$ ttria, ${ }^{1-3}$ although the conductivity decreases with increasing dopant concentration. The maximum conductivity below the transition temperature of $\delta$ $\mathrm{Bi}_{2} \mathrm{O}_{3}$ is therefore obtained at the minimum doping level necessary to stabilize the fcc phase. ${ }^{1}$ Doping with erbia or yttria has shown the best preservation of ionic conductivity. ${ }^{2}$ The conductivity of compositions $\mathrm{Bi}_{2-x}(\mathrm{Y}, \mathrm{Er})_{x} \mathrm{O}_{3}$ have been investigated extensively. ${ }^{1-7}$ In the $\mathrm{Bi}_{2-x} \operatorname{Er}_{x} \mathrm{O}_{3}$ system, the maximum conductivity is reached at 20 to 25 mole percent $(\mathrm{m} / \mathrm{o}) \mathrm{Er}(x=0.4$ to 0.5$) .{ }^{4}$ The ionic conductivity of $\mathrm{Bi}_{1.5} \mathrm{Er}_{05} \mathrm{O}_{3}$ (denoted as $\mathrm{BE} 25$ ) has an activation energy of $72 \pm 4 \mathrm{~kJ} / \mathrm{mol}$ above $873 \mathrm{~K}$ and reaches an absolute value of $25 \Omega^{-1} \mathrm{~m}^{-1}$ at $973 \mathrm{~K}$. The ionic conductivities of several compositions $\mathrm{Bi}_{2-x} \mathrm{Y}_{x} \mathrm{O}_{3}$ have been shown ${ }^{5,6}$ to be independent of oxygen pressure.

The partial electronic conductivity of $\mathrm{Bi}_{1.46} \mathrm{Y}_{0.54} \mathrm{O}_{3}$ at elevated temperatures has been investigated by Takahashi et $a l^{7}$ The electronic conductivity, $\sigma_{\mathrm{e}}$, is predominantly p-type at high oxygen pressures and has an activation energy, $E_{\text {act }}$, of $106 \mathrm{~kJ} / \mathrm{mol}$. In Kröger-Vink notation, ${ }^{3}$ the oxygen incorporation reaction under these conditions can be written as

$$
\frac{1}{2} \mathrm{O}_{2}+\mathrm{V}_{\mathrm{O}} \rightleftarrows \mathrm{O}_{\mathrm{O}}^{\times}+2 \mathrm{~h}^{*}
$$

Since the concentrations of oxygen anions $O_{0}^{\times}$and oxygen vacancies $V_{o}^{*}$ are virtually constant, it follows that

$$
\sigma_{\mathrm{e}} \propto\left[\mathrm{h}^{*}\right] \propto p_{\mathrm{O}_{2}}^{1 / 4}
$$

At low oxygen partial pressures $\left(p_{\mathrm{O}_{2}}<10^{-6}\right.$ to $10^{-8}$ bar $)$, n-type conductivity with a $-1 / 4$ dependence on oxygen pressure is predominant $\left(E_{\text {act }}=213 \mathrm{~kJ} / \mathrm{mol}\right)$. The literature on $\mathrm{Bi}_{2} \mathrm{O}_{3}$-based electrolytes has been reviewed recently. ${ }^{9}$

The surface exchange kinetics of $\mathrm{BE} 25$ has been investigated by Boukamp et al. ${ }^{10_{2}^{11}}$ by means of ${ }^{18} \mathrm{O} /{ }^{16} \mathrm{O}$ isotopic exchange. The following mechanism was proposed for the dissociative adsorption of oxygen in order to account for the $p_{\mathrm{O}_{2}}^{1 / 2}$ dependence of the exchange rate experimentally observed

$$
\begin{gathered}
\mathrm{O}_{2}+e^{\prime} \rightleftarrows \mathrm{O}_{2, \mathrm{ads}}^{-} \\
\mathrm{O}_{2, \mathrm{ads}}^{-}+e^{\prime} \rightleftarrows 2 \mathrm{O}_{\mathrm{ads}}^{-} \\
2 \mathrm{O}_{\mathrm{ads}}^{-}+2 \mathrm{~V}_{\mathrm{o}}+2 e^{\prime} \rightleftarrows 2 \mathrm{O}_{\mathrm{o}}^{\times}
\end{gathered}
$$

The second step in this scheme is thought to be rate determining.

The mutual occurrence of ionic and electronic conductivity makes it possible to use these materials as oxygen separation membranes in oxygen pressure gradients. The oxygen semipermeability of 0.2 to $2.85 \mathrm{~mm}$ thick dense BE25 membranes has been studied by Bouwmeester et $a{ }^{12}$ who found that permeability in the temperature range 883 to $1083 \mathrm{~K}$ in air/He gradients is determined partly by bulk diffusion of electron holes and partly by the oxygen exchange process at the gas/solid interfaces. In modeling the data, a $5 / 8$ power dependence of the oxygen exchange rate on oxygen partial pressure was assumed. Experimentally observed fluxes were in the range $10^{-3}$ to $0.1 \mathrm{mmol} \mathrm{m}^{-2} \mathrm{~s}^{-1}$.

Enhancement of both the electronic conductivity and the surface exchange of oxygen are therefore required to make application of $\mathrm{Bi}_{2-x}(\mathrm{Y}, \mathrm{Er})_{x} \mathrm{O}_{3}$-based membranes possible. The electronic conductivity can be increased to some extent by partial substitution of bismuth by terbium. ${ }^{13} \mathrm{An}$ aiternative approach is to disperse a percolative second 